\title{
Borrelia sp. phylogenetically different from Lyme disease- and relapsing fever-related Borrelia spp. in Amblyomma varanense from Python reticulatus
}

Wachareeporn Trinachartvanit', Supanee Hirunkanokpun ${ }^{3}$, Ronnayuth Sudsangiem', Wanwisa Lijuan ${ }^{4}$, Duangjai Boonkusol ${ }^{5}$, Visut Baimai ${ }^{1,2}$ and Arunee Ahantarig ${ }^{1,2^{*}}$

\begin{abstract}
Background: Species of the genus Borrelia are causative agents of Lyme disease and relapsing fever. Lyme disease is the most commonly reported vector-borne disease in the northern hemisphere. However, in some parts of the world Lyme borreliosis and relapsing fever may be caused by novel Borrelia genotypes. Herein, we report the presence of a Borrelia sp. in an Amblyomma varanense collected from Python reticulatus.

Methods: Ticks were collected from snakes, identified to species level and examined by PCR for the presence of Borrelia spp. flaB and $16 \mathrm{~S}$ rRNA genes. Phylogenetic trees were constructed using the neighbour-joining method.

Results: Three A. varanense ticks collected from P. reticulatus were positive for a unique Borrelia sp., which was phylogenetically divergent from both Lyme disease- and relapsing fever-associated Borrelia spp.

Conclusion: The results of this study suggest for the first time that there is a Borrelia sp. in A. varanense tick in the snake $P$. reticulatus that might be novel.
\end{abstract}

Keywords: Borrelia, Amblyomma varanense, Amblyomma pattoni, Tick, Thailand

\section{Background}

Tick infestation in snakes occurs worldwide and involves the following species: Amblyomma gervaisi in the northern region of western Ghats in India [1], Rhipicephalus sanguineus (sensu lato) in Malaysia [2], Amblyomma varanense and Amblyomma helvolum in Thailand [3, 4] and Amblyomma hydrosauri in Australia [5]. Hirunkanokpun et al. [6] detected several bacterial species in the national parks of Thailand, but no Borrelia spp. were found. The aim of this study was to determine the presence of Borrelia spp. within Amblyomma spp. ticks collected from five snake species. In addition, phylogenetic analyses of Borrelia spp. are also presented.

\footnotetext{
* Correspondence: arunee.aha@mahidol.ac.th

'Biodiversity Research Cluster, Department of Biology, Faculty of Science, Mahidol University, Rama 6 Road, Bangkok 10400, Thailand

${ }^{2}$ Center of Excellence for Vectors and Vector-Borne Diseases, Faculty of Science, Mahidol University at Salaya, Phutthamonthon 4 Road, Nakhon Pathom 73170, Thailand

Full list of author information is available at the end of the article
}

\section{Methods}

Tick collection and identification

Tick collection from snakes was performed in February 2014 in Lopburi Province, Thailand $\left(14^{\circ} 48^{\prime} 1.61^{\prime \prime} \mathrm{N}\right.$, $\left.100^{\circ} 38^{\prime} 10.75^{\prime \prime} \mathrm{E}\right)$. We observed snake scales to identify partial protrusions of tick bodies outside of the scales. Ticks were collected from the skin beneath the scales using forceps. Ticks were identified according to their morphology using standard taxonomic keys [7-11].

\section{DNA extraction and amplification}

The ticks were washed individually and homogenised in $200 \mu \mathrm{l}$ of $10 \times$ PBS solution. DNA extraction was performed using the QIAamp DNA Blood Mini Kit (Qiagen, Hilden, Germany). Oligonucleotide primer pairs FLA1-FLA2 (BflaPAD 5'-GAT CA(G/A) GC(T/ A) CAA (C/T)A TAA CCA(A/T) ATG CA-3'; BflaPBU, nest- 5'-GCT GAA GAG CTT GGA ATG CAA CC- 
3'; BflaPCR, nest-5'-TGA TCA GTT ATC ATT CTA ATA GCA-3'; BflaPDU 5' -AGA TTC AAG TCT GTT TTG GAA AGC-3') and 16S rDNA (16SF1 5'-ATA ACG AAG AGT TTG ATC CTG GC-3'; 16SR 5' -CAG CCG CAC TTT CCA GTA CG/3') were used in this study to identify target Borrelia DNA in the ticks $[7,8]$. The positive PCR products from tick samples were purified using a High Pure PCR product purification kit (Roche, Basel, Switzerland). Sequencing reactions were performed with BigDye Terminator v3.1 Cycle Sequencing Kits (Applied BioSystems, Waltham, Massachusetts, USA) based on the fluorescent-label terminator method. Sequencing products were analyzed using a Genetic Analyzer 3730XL automated DNA sequencing system (Applied BioSystems, Waltham, Massachusetts, USA).

\section{Phylogenetic analysis}

Phylogenetic trees were constructed using the neighbourjoining method (PAUP 4.0b1) [12]. DNA gaps or missing data were excluded from the analyses. Confidence values for individual branches of the resulting tree were determined by bootstrap analysis with 1000 replicates.

\section{Results and discussion}

Ticks were collected from the following five snake species: Python reticulatus, Ophiophagus hannah, Ptyas korros, Naja kaouthia and Elaphe radiata. Four Amblyomma varanense ticks (three males and one female) were collected from one $P$. reticulatus. One $A$. varanense tick (one female) and two Amblyomma pattoni (males) were collected from O. hannah. Two A. pattoni (males) were collected from $N$. kaouthia. In addition, two A. pattoni males

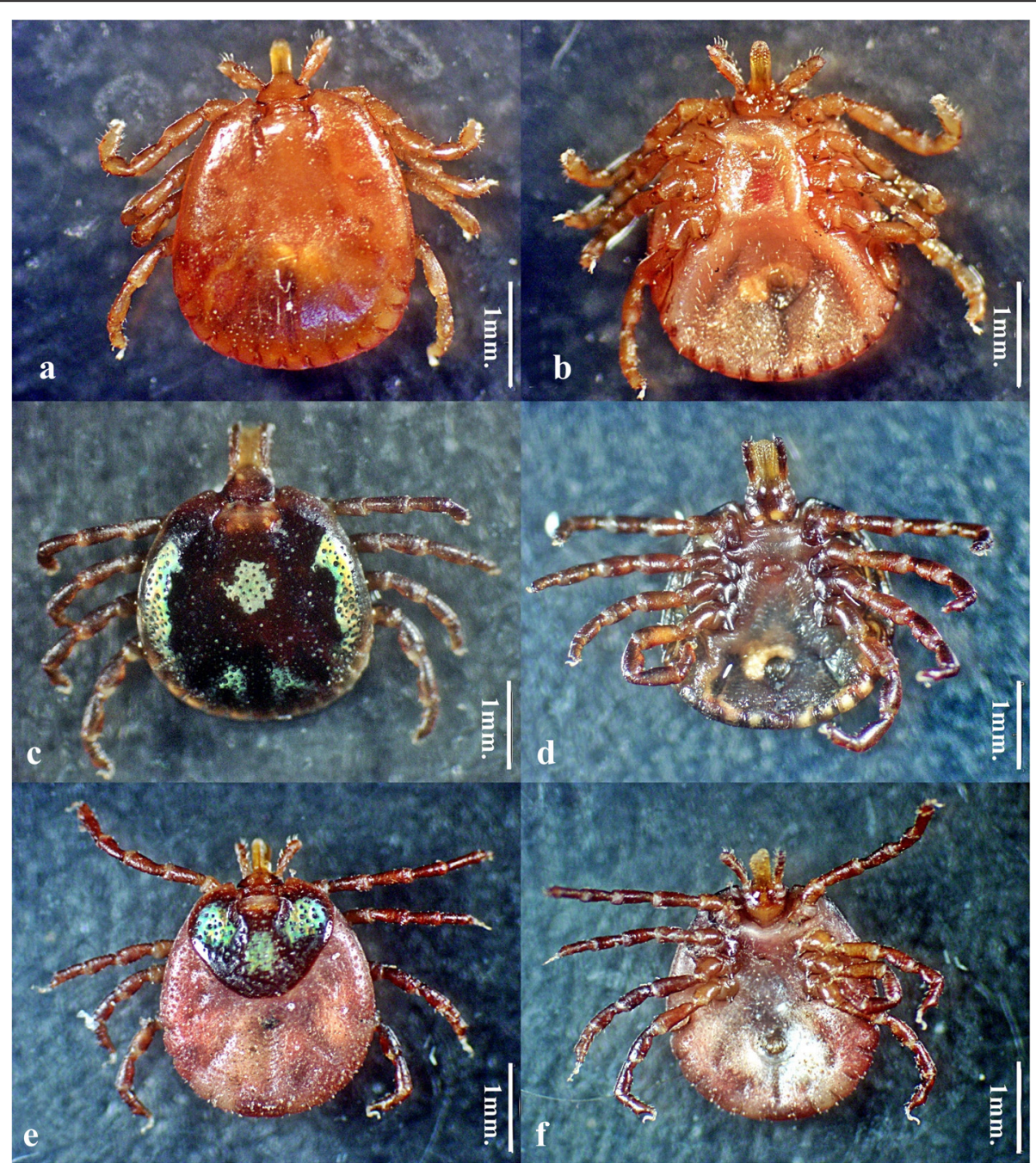

Fig. 1 Pictures of ticks identified in this study. a Amblyomma pattoni, male, dorsal view. b Amblyomma pattoni, male ventral view. c Amblyomma varanense, male, dorsal view. d Amblyomma varanense, male, ventral view. e Amblyomma varanense, female, dorsal view. f Amblyomma varanense, female, ventral view. Scale-bars: $1 \mathrm{~mm}$ 
were collected from $E$. radiata. Finally, one $A$. varanense tick (male) was collected from $E$. radiata. Tick species reported in this study have hypostomal dentition $3 / 3$. The male of $A$. pattoni has coxa I with an inconspicuous internal spur, which is sometimes fused with the more prominent external spur, and cervical pits are commashaped. The male of $A$. varanense has coxa I with the external spur noticeably longer than the internal and the female has coxa I with the internal spur smaller than the external spur, but always separated from the latter (Fig. 1).

A total of 12 ticks was collected from snakes and examined by PCR for the presence of the Borrelia spp. genes. Of these, three ticks, all identified as $A$. varanense isolated from $P$. reticulatus, were positive for Borrelia spp. No Borrelia spp. were detected in A. pattoni or in A. varanense collected from other snake species.

Borrelia sp. DNA sequences were compared with sequences in the NCBI GenBank database by nucleotide BLAST. The $16 S$ rRNA gene sequence of this Borrelia sp. is $100 \%$ identical (1449/1449 bp) to Borrelia sp. BF16 (GenBank: AB473538) and was submitted to GenBank and assigned as KU497718 (Borrelia sp. in Amblyomma varanense from Python reticulatus). The amplified PCR product of the flaB gene for flagellin was approximately $384 \mathrm{bp}$. A sequence analysis of the flaB gene for flagellin from the Borrelia-positive ticks revealed that this gene sequence is $99 \%$ similar (294/ $296 \mathrm{bp})$ to a sequence for Borrelia sp. BF16 flaB gene for flagellin (isolate BF16; GenBank: AB473488). The 384 bp Borrelia flaB consensus sequence was submitted to GenBank and assigned as Borrelia sp. KT758064. By contrast, this sequence was only $87 \%$ similar (337/387 bp) to the following: the $B$. turcica flaB gene for flagellin (strain IST4; GenBank: AB109244); B. turcica IST7 flagellin gene (GenBank: KF422815) (336/387 bp); and Borrelia sp. tAG66 M flaB gene for flagellin (GenBank: AB529322) (336/387 bp).

Phylogenetic trees were constructed using the neighbour-joining method (PAUP 4.0b1) [12]. Individual branch confidence values were determined by bootstrap analysis with 1000 pseudoreplicates (Figs. 2 and 3). The phylogenetic trees for both genes of Borrelia spp. inferred from the complete $16 \mathrm{~S}$ rRNA gene sequences (Fig. 2) and partial sequences of the flaB genes (Fig. 3) indicated that Borrelia sp. from the present study is related to Borrelia sp. (GenBank: AB473538) from reptiles and to B. turcica IST7 (GenBank: KF422815) flagellin gene, respectively, but belongs in a different group from Borrelia burgdorferi. The phylogenetic relationships among relapsing fever-associated Borrelia spp. and Lyme diseaseassociated Borrelia spp. were reported previously using rrs and $16 S$ rDNA [13, 14]. The flaB and $16 S$ rRNA gene sequences of Borrelia sp. of $A$. varanense from $P$. reticulatus isolated in this study, formed a separate branching root from both Lyme disease-associated Borrelia species and relapsing fever-associated Borrelia species.

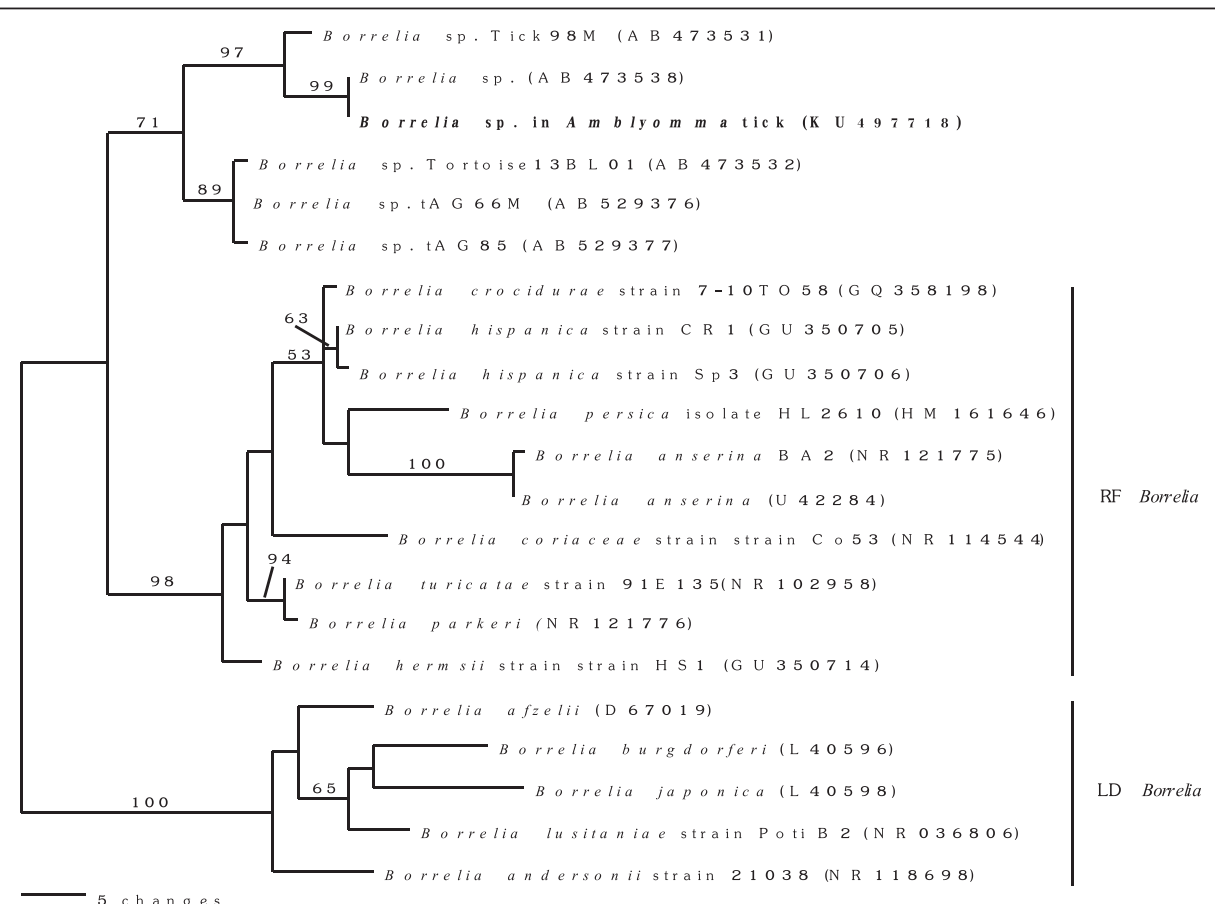

Fig. 2 Neighbour-joining phylogenetic analysis of Borrelia 165 rRNA gene sequences including the newly-generated KU497718 for Borrelia sp. in Amblyomma varanense from Python reticulatus 


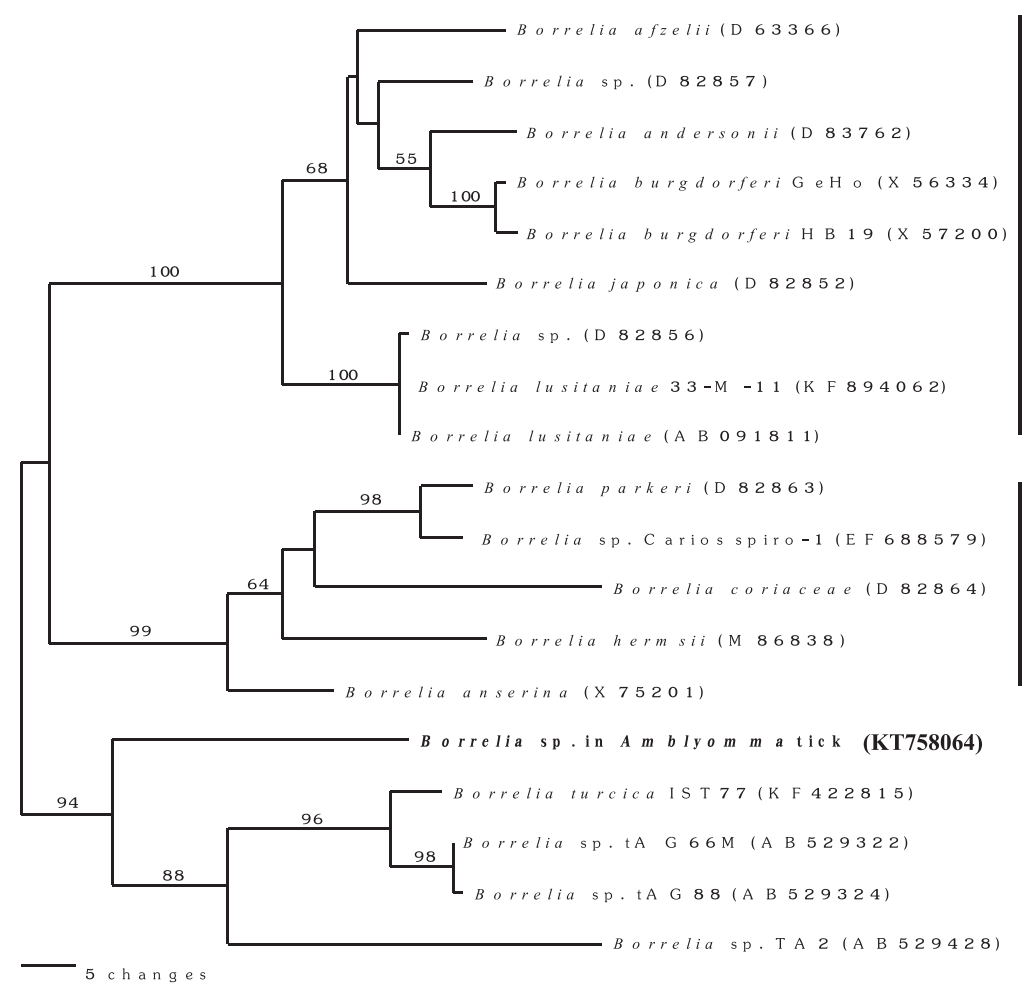

\section{LD Borrelia}

\section{RF Borrelia}

Fig. 3 Neighbour-joining phylogenetic analysis of Borrelia flaB gene sequences including the newly-generated KT758064 for Borrelia sp. in Amblyomma varanense from Python reticulatus

\section{Conclusion}

Our findings suggest that Borrelia sp. in A. varanense from $P$. reticulatus might be novel and phylogenetically divergent from both Lyme disease- and relapsing feverassociated Borrelia species.

\section{Acknowledgement}

This research project is supported by Mahidol University and a Higher Education Research Promotion grant (HERP, 2557A13162005).

\section{Funding}

This research project is supported by Mahidol University and a Higher Education Research Promotion grant (HERP, 2557A13162005).

\section{Availability of data and material}

The sequences for Borrelia sp. in Amblyomma varanense from Python reticulatus are submitted to the GenBank database under accession numbers KU497718 (16S rRNA) and KT758064 (flaB gene sequence).

\section{Authors' contributions}

WT and AA planned and designed the study. WL and DB carried out the field collection of samples. WT and AA carried out the majority of the laboratory and tick identification work. SH performed the phylogenetic analysis. RS generated 165 rRNA gene sequences of Borrelia and helped in identification section. WT and AA wrote the manuscript with some advice from VB. All authors read, discussed, and approved the final version of the manuscript.

\section{Competing interests}

The authors declare that they have no competing interests.

\section{Consent for publication}

Not applicable.
Ethics approval and consent to participate

Not applicable.

\section{Author details}

'Biodiversity Research Cluster, Department of Biology, Faculty of Science, Mahidol University, Rama 6 Road, Bangkok 10400, Thailand. ${ }^{2}$ Center of Excellence for Vectors and Vector-Borne Diseases, Faculty of Science, Mahidol University at Salaya, Phutthamonthon 4 Road, Nakhon Pathom 73170, Thailand. ${ }^{3}$ Department of Biology, Faculty of Science, Ramkhamhaeng University, Ramkhamhaeng Road, Bangkok 10240, Thailand. ${ }^{4}$ Department of Science Education, Faculty of Science and Technology, Thepsatri Rajabhat University, Maung, Lopburi 15000, Thailand. ${ }^{5}$ Department of Biology, Faculty of Science and Technology, Thepsatri Rajabhat University, Maung, Lopburi 15000, Thailand.

Received: 27 September 2015 Accepted: 7 June 2016

Published online: 24 June 2016

\section{References}

1. Pandit P, Bandivdekar R, Geevarghese G, Pande S, Mandke O. Tick infestation on wild snakes in northern part of western Ghats of India. J Med Entomol. 2011:48:504-7.

2. Mariana A, Vellayan S, Halimaton I, Ho TM. Acariasis on pet Burmese python, Python molurus bivittatus in Malasia. Asian Pac J Trop Med. 2011:4:227-8.

3. Sumrandee C, Hirunkanokpun S, Doornbos K, Kitthawee S, Baimai V, Grubhoffer L, Trinachartvanit W, Ahantarig A. Molecular detection of Rickettsia species in Amblyomma ticks collected from snakes in Thailand. Ticks Tick Borne Dis. 2014;5:632-40

4. Sumrandee C, Hirunkanokpun S, Grubhoffer L, Baimai V, Trinachartvanit W, Ahantarig A. Phylogenetic relationships of Francisella-like endosymbionts detected in two species of Amblyomma from snakes in Thailand. Ticks Tick Borne Dis. 2014;5:29-32. 
5. Stenos J, Graves S, Popov VL, Walker DH. Aponomma hydrosauri, the reptileassociated tick reservoir of Rickettsia honei on Flinders Island, Australia. Am J Trop Med Hyg. 2003;69:314-7.

6. Hirunkanokpun S, Kittayapong P, Cornet JP, Gonzalez JP. Molecular evidence for novel tick-associated spotted fever group rickettsiae from Thailand. J Med Entomol. 2003:40:230-7.

7. Wodecka B. Detection of Borrelia burgdorferi sensu lato DNA in Ixodes ricinus ticks in North-western Poland. Ann Agric Environ Med. 2003;10:171-8.

8. Masuzawa T, Takada N, Kudeken M, Fukui T, Yano Y, Ishiguro F, et al. Borrelia sinica sp. nov., a Lyme disease-related Borrelia species isolated in China. Int J Syst Evol Microbiol. 2001:51:1817-24.

9. Robinson L. Ticks. A monograph of the Ixodoidea. Part IV. The genus Amblyomma. Cambridge: Cambridge University Press; 1926.

10. Kohls GM. Malaysian parasites. XVIII. Ticks (Ixodoidea) of Borneo and Malaya. Stud Inst Med Res Malaya. 1957:28:65-94.

11. Takano A, Goka K, Une Y, Shimada Y, Fujita H, Shiino T, et al. Isolation and characterization of a novel Borrelia group of tick-borne borreliae from imported reptiles and their associated ticks. Environ Microbiol. 2010;134-146.

12. Swofford DL. PAUP*. Phylogenetic analysis using parsimony (*and other methods). Version 4.0 beta10. Sunderland: Sinaneur Associates; 2002

13. Ras NM, Lascola B, Postic D, Cutler SJ, Rodhain F, Baranton G, et al. Phylogenesis of relapsing fever Borrelia spp. Int J Syst Bacteriol. 1996:46:859-65.

14. Güner ES, Watanabe M, Hashimoto N, Kadosaka T, Kawamura Y, Ezaki T, et al. Borrelia turcica sp. nov., isolated from the hard tick Hyalomma aegyptium in Turkey. Int J Syst Evol Microbiol. 2004;54:1649-52.

\section{Submit your next manuscript to BioMed Central and we will help you at every step:}

- We accept pre-submission inquiries

- Our selector tool helps you to find the most relevant journal

- We provide round the clock customer support

- Convenient online submission

- Thorough peer review

- Inclusion in PubMed and all major indexing services

- Maximum visibility for your research

Submit your manuscript at www.biomedcentral.com/submit 